\title{
Erratum: Near-zero refractive index photonics
}

Iñigo Liberal and Nader Engheta

Nature Photonics 11, 149-158 (2017); published online 1 March 2017; corrected after print 6 March 2017.

Owing to technical problems, this Review Article was published online later than the date given in the print version. The published date should read '1 March 2017', and is correct in the online versions. 